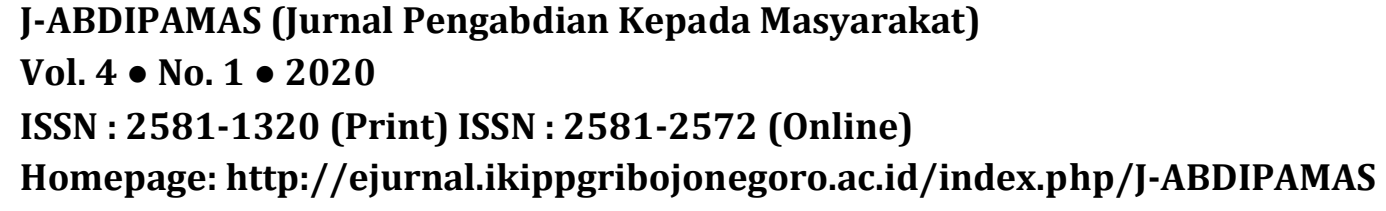

ISSN : 2581-1320 (Print) ISSN : 2581-2572 (Online)

Homepage: http://ejurnal.ikippgribojonegoro.ac.id/index.php/J-ABDIPAMAS

\title{
PENERAPAN DATA ANTROPOMETRI SISWA DALAM PERANCANGAN TEMPAT BERWHUDU DI SDIT ATH THAARIQ - 2 DUMAI
}

\author{
Fitra $^{1}$, Desyanti $^{2}$, Mustazihim Suhaidi $^{3}$ \\ ${ }^{1}$ Sekolah Tinggi Teknologi Dumai. Email: famukhtyfitra@gmail.com \\ 2Sekolah Tinggi Teknologi Dumai. Email: desyanti734@gmail.com \\ ${ }^{3}$ Sekolah Tinggi Teknologi Dumai. Email: muja.1708@gmail.com
}

\begin{abstract}
SDIT ATH-THAARIQ 2 Muhammadiyah Dumai is one of the integrated Islamic elementary schools in the city of Dumai, has a vision of realizing a generation of Qur'ani, Islamic civilized, intelligent, achievers, towards a global-minded human being. SDIT ATH-THAARIQ 2 Muhammadiyah Dumai accustoms their students to perform prayers in congregation and duha prayers every day, practice Islamic etiquette such as eating and drinking courtesy, courtesy at the toilet, courtesy to old parents, procedures for taking wudhu correctly and memorization of Juz Amma. To take whudu still use the water closet (WC) that available in each class with a size of $2 \mathrm{~m} \times 1 \mathrm{~m}$ and the school still provides 1 faucet so that when student take wudhu they have to queue. The initial observations of the position of the faucets in the WC were not appropriate with the anthropometry of the students of SDIT ATH-THAARIQ 2 Muhammadiyah Dumai. So we need a place of Wudhu that can meet the needs when taking wudhu by making a place of wudhu with the position of the tap in appropriate with the average anthropometric data of students of SDIT ATH-THAARIQ 2 Muhammadiyah Dumai. The results of wudhu place design with the application of anthropomteri data are the height of the faucet from the floor is $79.25 \mathrm{~cm}$, the width of the distance between the faucets is $50 \mathrm{~cm}$ and the body distance to the faucet is 30.80 $\mathrm{cm}$
\end{abstract}

Keywords: Anthropometry, SDIT ATH-THAARIQ 2 Muhammadiyah Dumai, Wudhu

\begin{abstract}
ABSTRAK
SDIT ATH-THAARIQ 2 Muhammadiyah Dumai merupakan salah satu sekolah dasar islam terpadu yang ada di Kota Dumai, memiliki visi mewujudkan generasi Qur'ani, beradab islami, cerdas, berprestasi, menuju insan berwawasan global. SDIT ATH-THAARIQ 2 Muhammadiyah Dumai membiasakan siswa-siswinya untuk melaksanakan sholat berjama'ah dan sholat dhuha setiap hari, mengamalkan adab - adab islami seperti adab makan dan minum, adab ke WC, adab kepada oarang tua, tata cara mengambil wudhu yang benar serta hafalan - hafalan Juz Amma. Untuk pengambilan whudu masih menggunakan water closet (WC) yang tersedia di setiap kelas dengan ukuran $2 m \times 1 m$ dan sekolah masih menyediakan 1 kran sehingga pada saat pengambilan air wudhu siswa - siswi harus mengantri. Hasil pengamatan awal posisi kran yang ada di WC belum sesuai dengan antropometri siswa-siswi SDIT ATH-THAARIQ 2 Muhammadiyah Dumai. Maka diperlukan tempat wudhu yang bisa memenuhi kebutuhan saat pengambilan air wudhu tersebut dengan membuat tempat wudhu yang posisi krannya sesuai rata-rata data antropometri siswa - siswi SDIT ATHTHAARIQ 2 Muhammadiyah Dumai. Hasil perancangan tempat berwudhu dengan penerapan data antropomteri adalah tinggi kran dari lantai adalah 79,25 cm, lebar jarak antara kran adalah $50 \mathrm{~cm}$ dan jarak tubuh ke kran adalah $30,80 \mathrm{~cm}$.
\end{abstract}

Kata kunci: Antropometri, SDIT ATH-THAARIQ 2 Muhammadiyah Dumai, Wudhu. 


\section{PENDAHULUAN}

SDIT ATH-THAARIQ 2 Muhammadiyah Dumai merupakan satu salah sekolah dasar islam terpadu yang ada di kota Dumai, memiliki visi mewujudkan generasi Qur'ani, beradab islami, cerdas, berprestasi, menuju insan berwawasan global. SDIT ATHTHAARIQ 2 Muhammadiyah Dumai membiasakan siswa-siswinya untuk melaksanakan sholat berjama'ah dan sholat dhuha setiap hari, mengamalkan adab - adab islami seperti adab makan dan minum, adab ke WC, adab kepada orang tua, tata cara mengambil whudu yang benar serta hafalan - hafalan Juz Amma.

Tempat berwudhu SDIT ATH-THAARIQ 2 Muhammadiyah Dumai masih menggunakan water closet (WC) yang tersedia di setiap kelas dengan ukuran $2 \mathrm{~m} \times 1 \mathrm{~m}$ yang dapat dilihat pada Gambar 1 dan sekolah masih menyediakan 1 kran sehingga pada saat pengambilan air wudhu siswa - siswi harus mengantri terlebih dahulu. Hasil pengamatan awal posisi kran yang ada di WC tersebut belum sesuai dengan antropometri siswa - siswa SDIT ATH-THAARIQ 2 Muhammadiyah Dumai. Jumlah siswa - siswi SDIT ATH-THAARIQ 2 Muhammadiyah Dumai sebanyak 164 siswa-siswi yang terdiri dari kelas 1 sampai kelas 5 . Kelas 1 terdiri dari 2 lokal, kelas 2 terdiri dari 2 lokal dan kelas 3, 4 dan 5 masing - masing 1 lokal dengan jumlah siswa rata- rata 23 orang perkelas. Dengan hanya menghadalkan 1 kran dari setiap WC kelas tidak dapat memenuhi kebutuhan siswa untuk mengambil air wudhu. Maka diperlukan tempat wudhu yang bisa memenuhi kebutuhan saat pengambilan air wudhu tersebut. Salah satu prinsip dasar ergonomi dalam perancangan adalah suatu rancangan hendaknya memperhatikan faktor manusia sebagai pengguna yang mempunyai berbagai keterbatasan secara individu (human-centered design) (Iridiastadi dan Yassierli, 2014).

Aspek dimensi fisik merupakan salah satu hal mendasar yang harus dipertimbangkan dalam perancangan untuk mendapatkan produk yang ergonomis. Dengan memperhatikan aspek karakteristik pengguna, maka kenyamanan, kepuasan, keselamatan kerja, dan tingkat produktivitas dapat diperbaiki. Antropometri merupakan ilmu yang berhubungan dengan aspek ukuran fisik manusia. Aspek fisik ini tidak hanya dimensi linier, tetapi juga berupa berat badan. Keilmuan ini melingkupi metode pengukuran dan permodelan dimensi tubuh manusia, serta teknik aplikasi untuk perancangan (Iridiastadi dan Yassierli, 2014).

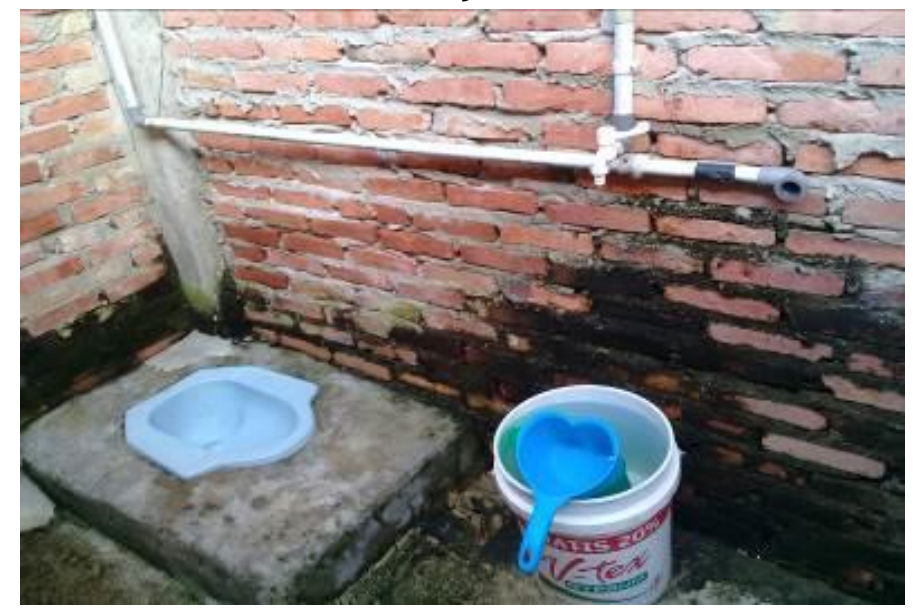

Gambar 1. Kondisi tempat whudu siswa 
Ergonomi berasal dari bahasa latin yaitu "Ergo" yang berarti kerja dan "Nomos" yang berarti hokum alam dan dapat didefinisikan sebagai studi tentang aspek-aspek manusia dalam lingkungan kerjanya yang ditinjau secara anatomi, fisiologi, psikologi, engineering, manajemen dan design (perancangan) Ergonomi berkenaan pula dengan otpimasi, efisiensi, kesehatan, keselamatan, dan kenyamanan manusia di tempat kerja, di rumah, dan tempat rekreasi (Nurmianto, 2008). Menurut Wignjosoebroto (2000) kata antropometri berasal dari bahasa Yunani (Greek), yaitu anthropos yang berarti manusia (man, human) dan metrein (to measure) yang berarti ukuran. Beberapa prinsip ergonomi yang dapat dipergunakan sebagai pegangan untuk merancang atau mengkritik suatu sistem kerja menurut Nurmianto (2008) adalah: 1) Sikap tubuh dalam bekerja dipengaruhi oleh bentuk, susunan, ukuran dan penempatan mesin-mesin, alat-alat penunjuk, cara pengoperasian mesin, 2) Untuk normalisasi ukuran mesin dan alat-alat industri harus diambil ukuran terbesar sebagai dasar serta diatur dengan suatu cara sehingga ukuran tersebut dapat dikecilkan.

Sedangkan Antropometri merupakan salah satu bagian yang menunjang Ergonomi, khususnya dalam perancangan suatu peralatan berdasarkan prinsip-prinsip Ergonomi. Istilah Antropometri berasal dari kata "Anthropos" yang berarti manusia dan "Metricos" yang berarti ukuran. Antropometri merupakan ilmu yang berhubungan dengan aspek ukuran fisik manusia (Iridiastadi dan Yassierli, 2014). Data Antropometri jelas diperlukan agar rancangan suatu produk bisa disesuaikan dengan orang yang akan mengoperasikannya. Ukuran tubuh yang diperlukan pada hakikatnya tidak sulit diperoleh dari pengukuran secara individual (Nurmianto, 2008). Selanjutnya penetapan nilai persentil (percentile) akan dilakukan sesuai dengan ketentuan yang ada dalam tabel probabilitas distribusi normal (Wignjosoebroto, 1995).

\section{METODE PELAKSANAAN}

Studi lapangan dilakukan oleh pengusul sebelum mengusulkan program kemitraan masyarakat, pengusul melakukan studi lapangan ke daerah calon mitra. Dalam melakukan studi ini pengusul menggunakan metode observasi dan wawancara terhadap pihak sekolah.

SDIT ATH-THAARIQ 2 Muhammadiyah Dumai menggunakan tempat berwudhu yang tersedia pada water closet (WC) di setiap kelas dengan ukuran $2 \mathrm{~m} \times 1 \mathrm{~m}$ dan sekolah masih menyediakan 1 kran sehingga pada saat pengambilan air wudhu siswa siswi harus mengantri terlebih dahulu. Hasil pengamatan awal posisi kran yang ada di WC tersebut belum sesuai dengan antropometri siswa-siswi SDIT ATH-THAARIQ 2 Muhammadiyah Dumai.

Metode yang ditawarkan dalam Program Kemitraan Masyarakat ini adalah penerapan data antropometri siswa-siswi pada perancangan tempat pengambilan air wudhu. Penerapan data antropometri dapat dilakukan jika tersedia nilai mean (ratarata) dan SD (standar deviasi) nya dari suatu distribusi normal. Adapun distribusi normal ditandai dengan adanya nilai mean dan SD. Sedangkan percentil adalah suatu nilai yang menyatakan bahwa percentace tertentu dari sekelompok orang yang 
dimensinya sama dengan atau lebih rendah dari nilai tersebut. Sebagai contoh, 95\% populasi adalah sama dengan atau lebih rendah dari 95 percentil, 5\% dari populasi berada sama dengan atau lebih rendah dari 5 percentil. Besarnya nilai percentile dapat ditentukan dari tabel probabilitas distribusi normal.

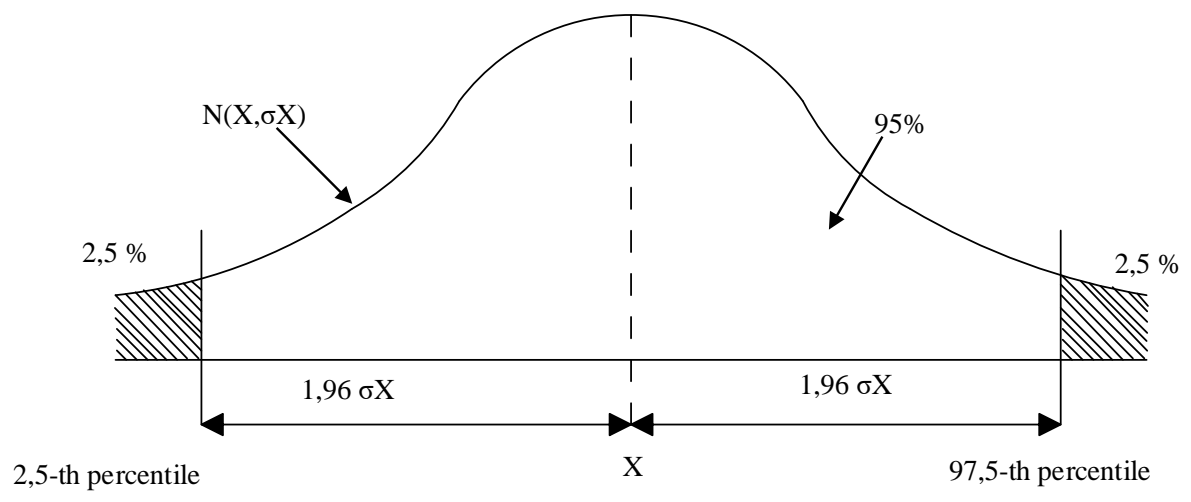

\begin{tabular}{ll}
\hline Persentil & Perhitungan \\
\hline $1^{\text {st }}$ & $\mathrm{X}-2.325 \sigma x$ \\
$2.5^{\text {th }}$ & $\mathrm{X}-1.960 \sigma x$ \\
$5^{\text {th }}$ & $\mathrm{X}-1.645 \sigma x$ \\
$10^{\text {th }}$ & $\mathrm{X}-1.280 \overline{\sigma x}$ \\
$50^{\text {th }}$ & \\
$90^{\text {th }}$ & $\mathrm{X}+1.280 \sigma x$ \\
$95^{\text {th }}$ & $\mathrm{X}+1.645 \sigma x$ \\
$97.5^{\text {th }}$ & $\mathrm{X}+1.960 \sigma x$ \\
$99^{\text {th }}$ & $\mathrm{X}+2.325 \sigma x$ \\
\hline
\end{tabular}

Gambar 2. Distribusi Normal dan Perhitungan Persentil (Nurmianto, 2008)

Sembilan puluh lima percentil menunjukkan tubuh berukuran besar, sedangkan 5 percentil menunjukkan tubuh berukuran kecil. Jika diinginkan dimensi untuk mengakomodasi 95\% populasi maka 2,5 dan 97,5 percentil adalah batas ruang yang dapat dipakai.

Sebelum melaksanakan kegiatan perlu ditetapkan prosedur kerja dengan tujuan setiap kegiatan yang dilaksanakan terarah. Prosedur kerja diawali dengan menetapkan mitra kerja. Dalam hal ini mitra kerja akan diajak berdiskusi dan memberikan informasi yang dibutuhkan oleh tim pengusul, kemudian dilakukan penerapan dan penggunaan teknologi yang ada. Kegiatan ini direncanakan akan dilakukan selama sekitar delapan bulan.

Peran serta mitra dalam pelaksanaan program kemitraan masyarakat ini sangat diharapkan, karena mitra yang lebih memahami karakteristik dan kondisi yang ada di lapangan. Kelebihan dan kemampuan mitra bila digabungkan dengan teknologi yang ditawarkan diharapkan akan menghasilkan luaran yang optimal dalam proses pelaksanaan kegiatan. 
Luaran yang ingin dicapai adalah dengan adanya tempat berwuhdu siswa yang posisi krannya sesuai rata-rata data antropometri siswa - siswi SDIT ATH-THAARIQ 2 Muhammadiyah Dumai agar siswa bisa membuka kran air sesuai dengan tinggi sikunya.

Tempat whudu yang akan dibangun dapat dilihat pada Gambar 3. Sebelum tempat whudu dibangun terlebih dahulu pengusul melakukan pengukuran data antropometri siswa dan siswi pada SDIT ATH-THAARIQ 2 Dumai dengan menggunakan kursi antropometri. Dimana data antropometri yang akan diambil adalah tinggi siku saat berdiri untuk digunakan sebagai tinggi dari kran air whudu. Data antropometri yang diambil adalah data seluruh siswa - siswi SDIT ATHTHAARIQ 2 Dumai yang berjumlah 164 siswa. Setelah data diperoleh lalu dilakukan perhitungan untuk menentukan tinggi kran dengan mempertimbangkan percentil ataupun kelonggaran sehingga tinggi kran yang akan dibangun bisa digunakan oleh seluruh siswa. Setelah perhitungan data antropometri selesai diolah kemudian dibuat bangunan tempat berwhudu yang berukuran panjang 3 meter, lebar 3 meter dan tinggi 2 meter. Selain itu akan dibangun juga WC yang berjumlah 1 unit. Untuk menampung air digunakan politank yang berkapasitas 500liter dimana air tesebut berasal dari PDAM Dumai.

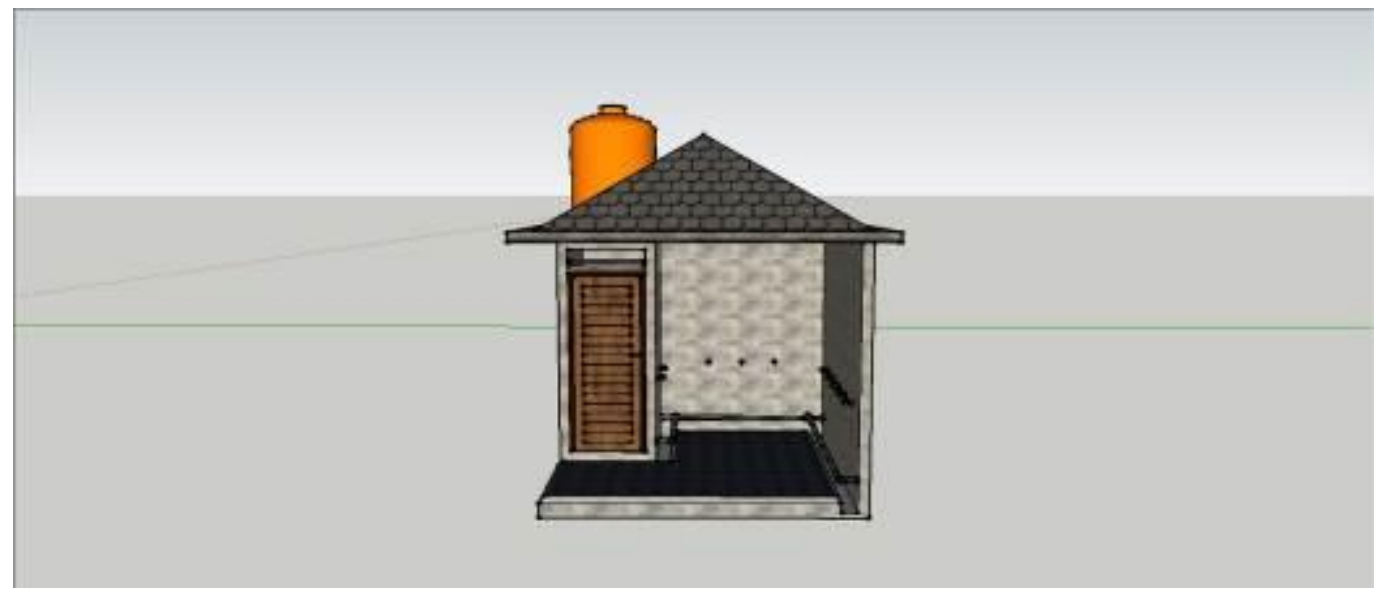

Gambar 3. Tempat Berwhudu yang akan dibangun

\section{HASIL DAN PEMBAHASAN}

Alat dan bahan yang digunakan pada pelaksanaan pengukuran dimensi tubuh adalah sebagai berikut:

a. Kursi antropometri, digunakan untuk mengukur seluruh bagian dimensi tubuh.

b. Meteran, digunakan untuk mengukur dimensi tubuh secara manual.

c. Satu buah batang kayu, digunakan untuk membantu pengukuran dimensi tubuh yang sulit dijangkau.

d. Lembar data antropometri, digunakan untuk mencatat keseluruhan hasil pengukuran.

e. Alat tulis, digunakan untuk menulis pada lembaran antropometri.

f. Kamera, digunakan untuk memotret kegiatan pada pengukuran data setiap anggota. 
Langkah-langkah dalam pengambilan data antropometri adalah sebagai berikut:

a. Persiapkan perlatan dan bahan yang dibutuhkan.

b. Mengukur dimensi tubuh yang diperlukan untuk penyesuaian terhadap produk dimana dimensi tubuh yang diukur sebanyak 3 dimensi dapat dilihat pada Tabel 3.1 data dimensi tubuh.

c. Hasil pengukuran dicatat keformulir data dimensi tubuh yang telah disiapkan.

d. Mendokumentasi pengukuran dengan memotret menggunakan kamera.

e. Lakukan pengukuran yang sama untuk setiap siswa mulai dari kelas 1 A, 1 B, 2 A, 2 B, 3,4 dan 5 .

Hasil pengamatan dan pengukuran dimensi tubuh yang telah dilakukan dengan menggunakan kursi antropometri dapat dilihat pada Tabel 9 sebagai berikut:

Tabel 1 . Data Dimensi Tubuh.Siswa SD IT Ath Thoriq 2 Muhammadiyah Dumai

\begin{tabular}{|c|c|c|c|c|c|c|c|c|c|c|c|}
\hline \multirow[b]{2}{*}{ No. } & \multirow[b]{2}{*}{ Dimensi } & \multirow[b]{2}{*}{ Keterangan } & \multicolumn{7}{|c|}{ Rata - Rata Ukuran $(\mathrm{cm})$} & \multirow{2}{*}{$\begin{array}{l}\text { Jumlah } \\
\text { (cm) }\end{array}$} & \multirow{2}{*}{$\begin{array}{l}\text { Rata- } \\
\text { Rata } \\
\text { (cm) }\end{array}$} \\
\hline & & & $\begin{array}{c}\text { Kelas } \\
1 \mathrm{~A}\end{array}$ & $\begin{array}{c}\text { Kelas } \\
1 \mathrm{~B}\end{array}$ & $\begin{array}{c}\text { Kelas } \\
2 \mathrm{~A}\end{array}$ & $\begin{array}{c}\text { Kelas } \\
2 \text { B }\end{array}$ & $\begin{array}{c}\text { Kelas } \\
3\end{array}$ & $\begin{array}{c}\text { Kelas } \\
4\end{array}$ & $\begin{array}{c}\text { Kelas } \\
5\end{array}$ & & \\
\hline 1. & $\begin{array}{l}\text { Tinggi } \\
\text { Siku }\end{array}$ & $\begin{array}{l}\text { Tinggi } \\
\text { Kran }\end{array}$ & 73,81 & 74,69 & 75,75 & 80,18 & 77,27 & 83,43 & 89,63 & 554,76 & 79,25 \\
\hline 2. & $\begin{array}{l}\text { Lebar } \\
\text { Bahu }\end{array}$ & $\begin{array}{l}\text { Lebar } \\
\text { antara kran } \\
1 \text { ke kran } 2 \\
\text { dan } \\
\text { seterusnya }\end{array}$ & 29,69 & 29,48 & 30,73 & 29,66 & 32,68 & 34,38 & 34,38 & 216,31 & 30,90 \\
\hline 3. & $\begin{array}{l}\text { Jarak } \\
\text { dari siku } \\
\text { ke ujung } \\
\text { Jari }\end{array}$ & $\begin{array}{l}\text { Jarak kran } \\
\text { ke tubuh }\end{array}$ & 32,27 & 32,57 & 34,27 & 36,73 & 35,66 & 36,61 & 40,66 & 248,77 & 35,54 \\
\hline
\end{tabular}

Data pengamatan yang didapat akan diolah dengan menggunakan rumus yang telah ditentukan. Perhitungan menggunakan tiga rumus untuk standar deviasi, menghitung nilai persentil dan hasil pengolahan data. Perhitungan dapat dilakukan seperti berikut:

\section{Menentukan Tinggi Kran}

Menentukan tinggi kran menggunakan dimensi tinggi siku berdiri dari lantai.

a. Rata-rata

$$
\begin{aligned}
& \overline{\mathrm{x}}=\sum_{\mathrm{i}=1}^{\mathrm{n}} \mathrm{xi} \mathrm{n} \\
& \overline{\mathrm{x}}=\frac{73,81+74,69+75,75+80,18+77,27+83,43+89,63}{7}=\frac{554,76}{7}=79,25 \mathrm{~cm}
\end{aligned}
$$

b. Standar deviasi

$$
\mathrm{S}=\sqrt{\frac{\sum_{i}^{n}\left(x_{i}-\bar{x}\right)^{2}}{n-1}}
$$




$$
\begin{aligned}
& S=\sqrt{\frac{(73,81-79,25)^{2}+(74,69-79,25)^{2}+\ldots \ldots+(89,63-79,25)^{2}}{7-1}} \\
& S=5,67 \mathrm{~cm}
\end{aligned}
$$

c. Persentil $\left(\mathrm{P}_{50}\right)$

$$
\begin{aligned}
& \mathrm{P}_{50}=\bar{x}_{+} \mathrm{k}_{1} \cdot \mathrm{S} \\
& \mathrm{P}_{50}=79,25+(0) \times 5,67 \\
& \mathrm{P}_{50}=79,25+0=79,25 \mathrm{~cm}
\end{aligned}
$$

Persentil sedang $\left(\mathrm{P}_{50}\right)$ digunakan agar siswa yang tinggi siku pendek tidak terlalu jauh menjangkaunya dan yang tinggi siku panjang tidak terlalu membungkuk untuk menggunakan krannya.. Jadi, tinggi kran dari lantai adalah 79,25 cm.

\section{Menentukan Jarak antara kran}

Menentukan jarak antara kran menggunakan dimensi lebar bahu.

a. Rata-rata

$$
\begin{aligned}
& \overline{\mathrm{x}}=\sum_{\mathrm{i}=1}^{\mathrm{n}} \mathrm{xi} \mathrm{h} \\
& \overline{\mathrm{x}}=\frac{29,69+29,48+29,69+30,73+29,66+32,68+34,38}{7}=\frac{216,31}{7}=30,90 \mathrm{~cm}
\end{aligned}
$$

b. Standar deviasi

$$
\begin{aligned}
& \mathrm{S}=\sqrt{\frac{\sum_{\mathrm{i}}^{\mathrm{n}}\left(\mathrm{x}_{\mathrm{i}}-\overline{\mathrm{x}}\right)^{2}}{\mathrm{n}-1}} \\
& \mathrm{~S}=\sqrt{\frac{(29,69-30,90)^{2}+(29,48-30,90)^{2}+\ldots . .+(34,38-30,90)^{2}}{7-1}} \\
& \mathrm{~S}=1,91 \mathrm{~cm}
\end{aligned}
$$

c. Persentil ( $\left.\mathrm{P}_{95}\right)$

$$
\begin{aligned}
& \mathrm{P}_{95}=\bar{x}_{+} \mathrm{k}_{1} \cdot \mathrm{S} \\
& \mathrm{P}_{95}=30,90+(1,645) \times 1,91 \\
& \mathrm{P}_{95}=30,90+3,14=34,04 \mathrm{~cm}
\end{aligned}
$$

Persentil besarl $\left(\mathrm{P}_{95}\right)$ digunakan agar yang memiliki bahu yang lebar tidak kesempitan saat mengambil wudhu. Dikarenakan saat pengambilan air wudhu ada lengan yang terbuka, maka diberi kelonggaran lengen terbuka kiri dan kanan yaitu $15,96 \mathrm{~cm}$. Jadi, lebar jarak antara kran adalah34,04+15,96=50 cm

\section{Menentukan Jarak Tubuh ke Kran}

Menentukan jarak tubuh ke kran wudhu menggunakan dimensi jarak siku ke ujung jari. 
a. Rata-rata

$$
\begin{aligned}
& \overline{\mathrm{x}}=\sum_{\mathrm{i}=1}^{\mathrm{n}} \mathrm{xi} / \mathrm{n} \\
& \overline{\mathrm{x}}=\frac{32,27+32,57+34,27+36,73+35,66+36,61+40,66}{7}=\frac{248,77}{7}=35,54 \mathrm{~cm}
\end{aligned}
$$

b. Standar deviasi

$$
\begin{aligned}
& S=\sqrt{\frac{\sum_{i}^{n}\left(x_{i}-\bar{x}\right)^{2}}{n-1}} \\
& S=\sqrt{\frac{(32,27-35,54)^{2}+(32,57-35,54)^{2}+\ldots .+(40,66-35,54)^{2}}{7-1}} \\
& S=2,88 \mathrm{~cm}
\end{aligned}
$$

c. Persentil ( $\left.\mathrm{P}_{5}\right)$

$$
\begin{aligned}
& \mathrm{P}_{5}=\bar{x}_{+} \mathrm{k}_{1} \cdot \mathrm{S} \\
& \mathrm{P}_{5}=35,54+(-1,645) \times 2,88 \\
& \mathrm{P}_{5}=35,54-4,74=30,80 \mathrm{~cm}
\end{aligned}
$$

Persentil kecil $\left(\mathrm{P}_{5}\right)$ digunakan agar yang jarak siku nya pendek bisa menjangkau kran dan nyaman saat menggunakannya. Jadi, jarak tubuh ke kran adalah 30,80 cm.

Setelah penerapan antropometri di lakukan maka di dapatkan ukuran untuk kran air wudhu SD IT Ath Thoriq 2 dapat dilihat pada Tabel 10.

Tabel 2. Ukuran Posisi Kran Wudhu

\begin{tabular}{lll}
\hline No & \multicolumn{1}{c}{ Keterangan } & Ukuran $(\mathrm{cm})$ \\
\hline 1 & Tinggi Kran & 79,25 \\
2 & Lebar antara kran 1 ke kran 2 dan seterusnya & 50 \\
3 & Jarak kran ke tubuh & 30,80 \\
\hline
\end{tabular}

Tempat berwudhu yang telah selesai di buat dapat di lihat pada Gambar 4 . Penerapam data antropometri adalah posisi kran untuk pengambilan air wudhu.

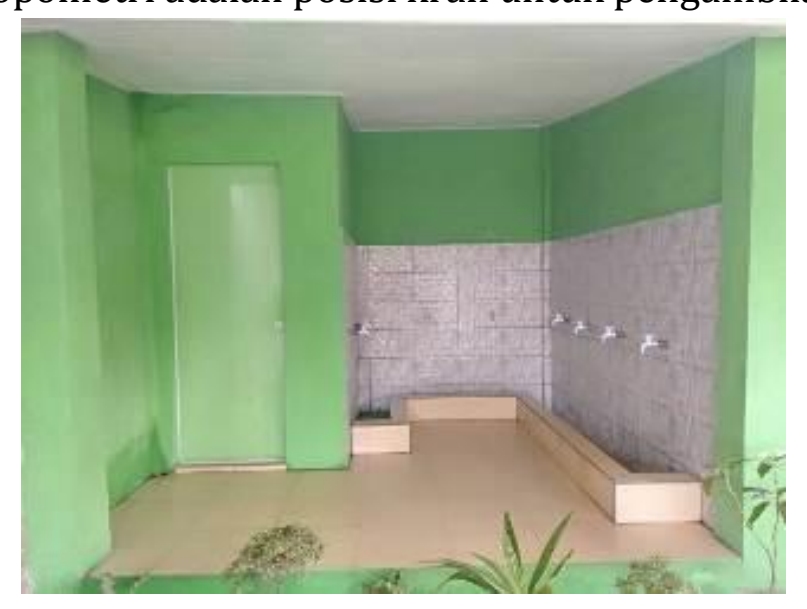

Gambar 4. Tempat Berwhudu yang selesai 


\section{SIMPULAN}

Hasil perancangan tempat berwudhu dengan penerapan data antropomteri siswasiswi SDIT ATH THAARIQ 2 Muhammadiyah Dumai untuk tinggi kran dari lantai adalah $79,25 \mathrm{~cm}$ yang di ambil dari dimensi tinggi siku siswa-siswi saat berdiri, lebar jarak antara kran adalah $50 \mathrm{~cm}$ dengan menggunakan dimensi lebar bahu siswa-siswi sedangkan jarak tubuh ke kran menggunakan dimensi jarak siku ke ujung jari adalah $30,80 \mathrm{~cm}$.

\section{UCAPAN TERIMA KASIH}

Ucapan terima kasih disampaikan kepada 1) Direktorat Riset dan Pengabdian Masyarakat Direktorat Jendral Penguatan Riset dan Pengembangan Kementrian Riset, Teknologi dan Pendidikan Tinggi Sesuai Kontrak Pengabdian Kepada Masyarakat Tahun Anggaran 2019 Nomor: SP DIPA-042.06.1.401516/2019, 2) SD IT ATH THAARIQ 2 MUHAMMADIYAH DUMAI

\section{DAFTAR RUJUKAN}

Iridiastadi, H., dan Assierli. (2014). Ergonomi suatu pengantar. Bandung, Indonesia: PT Remaja Rosdakarya.

Nurmianto, E. (2008). Ergonomi konsep dasar dan aplikasinya edisi kedua. Surabaya, Indonesia: Guna Widya.

Wignjosoebroto, S. (1995). Ergonomi, studi gerak dan waktu: Teknik analisis untuk peningkatan produktivitas kerja. Jakarta, Indonesia: Guna Widya.

Wignjosoebroto, S. (2000). Prinsip-prinsip perancangan berbasiskan dimensi tubuh (antropometri) dan perancangan stasiun kerja I, laboratorium ergonomi \& perancangan sistem kerja. Jurusan Teknik Industri FTI-ITS. msritomo/meitb/2000. 
10 J-Abdipamas, Vol. 4, No. 1 April, 2020 